\title{
Petrus Hispanus, médico medieval, elegido Papa con el nombre de Juan XXI. Bosquejo de la medicina en la Edad Media
}

\author{
Enrique Laval
}

Pontificia Universidad Católica de Chile.

Facultad de Medicina, Programa de Estudios Médicos Humanísticos.

Recibido: 22 de julio de 2013

Correspondencia a: Enrique Laval Román revinf@sochinf.cl

\author{
Petrus Hispanus, medieval physician elected as Pope named John XXI. \\ Sketck of medicine in the Middle Age
}

The Pope John XXI, named Pedro Rebuli Guiliani, was born in Lisbon, Portugal, around 1215. Known as Petrus Hispanus, Master Jullian, Peter of Spain, among other names. Besides medical studies, he studied Theology , Aristotelic Physics and Metaphysics at the University of Paris. He was named Professor of Medicine and Ophthalmology at the University of Sienna in 1247. In addition to several works about medicine, logic, and phylosophy, he authored the Tesaurus Pauperum ("Treasure of the Poor"), a prescription handbook of home-made, simple and cheap remedies. He was archbishop of Braga and Cardinal in 1272 and 1273, respectively. Elected Pope in 1276, he died tragically on May 20, 1277. Precedes this article a sketch of Medieval Medicine with emphasis on the XII and XIII centuries.

Key words: Middle Age, XII and XIII Centuries; Petrus-Hispanus medieval physician, Pope John XXI.

Palabras clave: Edad Media siglo XII y XIII; Petrus-Hispanus médico medieval; Papa Juan XXI.

\section{Sobre la Edad Media}

$\sqrt{1}$ 1 período histórico conocido como Edad Media comprende desde la caída del Imperio Romano de Occidente el año $476 \mathrm{dC}$, hasta el Renacimiento en el siglo XV. Como fechas exactas podrían consignarse las de la invención de la imprenta, entre 1440 y 1450 o la caída de Constantinopla en manos de los turcos, en 1453.

Se acostumbra considerar la Edad Media como un período de regresión en el saber científico, incluyendo la Medicina y siendo costumbre que los autores de habla inglesa se refirieran a ella como "Edad Oscura" ( "Dark Age"). Aunque en ciertos aspectos, es preciso reconocer que hubo una detención del progreso científico, especialmente hasta el siglo X, hay que recordar que durante este período, se sentaron las bases que permitieron el futuro Renacimiento de las Artes, las Letras y las Ciencias.

Las fuerzas históricas que construyeron el mundo médico medieval fueron tres: el Imperio Bizantino o Romano de Oriente, cuya capital Bizancio (llamada después Constantinopla) fue un verdadero centro de atesoramiento y recopilación científica; el Mundo Islámico o musulmán, que llegó a comprender casi la mitad del mundo conocido en ese entonces. En las ciudades de Bagdad (Califato de Oriente) y Córdoba (Califato de Occidente) se alcanzó el máximo desarrollo científico-cultural de la época; y Europa Occidental, en cuyos monasterios y universidades se cultivó la ciencia greco-romana, iniciándose la asistencia y educación médica organizada ${ }^{1,2}$.

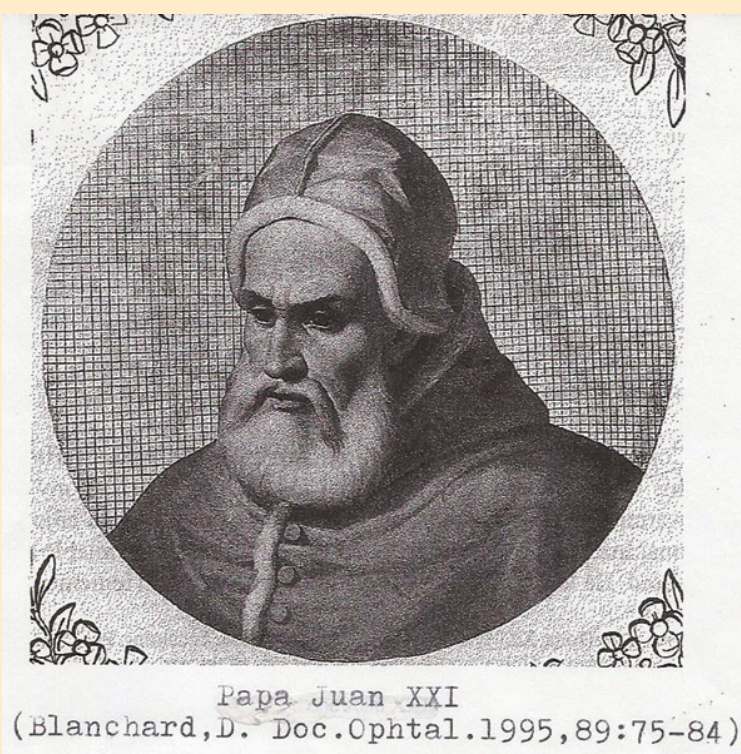

El gran historiador de la medicina argentina Aníbal Ruiz Moreno afirma que "los que llaman a la Edad Media época oscura o atrasada, lo hacen debido a la oscuridad o atraso de sus conocimientos. Los estudios serios, modernos e imparciales deben hacer cambiar la errónea y difundida idea que se tenía de dicha época. Sin embargo, no conviene exagerar la nota y creer que fue la más luminosa de la historia. "In medio veritas". 
Fue un periodo que tuvo, como todos, su parte buena y su parte mala, una época de transición, de prueba, pero nunca de atraso. Es necesario estudiarla bien, profunda y serenamente, sin prejuicios y con gran conocimiento de la cultura general antigua y moderna, para recién poder apreciarla"3.

\section{La medicina en la Edad Media}

\section{Medicina monástica}

Hasta mediados de la Alta Edad Media, la medicina se ejerció principalmente en los monasterios, por parte de los monjes circunscrita a su misión caritativa. Galeno era la autoridad indiscutible. De sus obras se dedujo la tesis del "pus laudabilis", según la cual el pus era un producto natural que favorecía la curación de las heridas, lo que hizo más difícil el progreso de su tratamiento.

La medicina medieval tuvo un carácter marcadamente especulativo: la teoría médica constituía lo sustantivo. La labor manual era desdeñada. Así, la práctica quirúrgica fue quedando en manos de los barberos. En 1163 se formuló el famoso edicto del Concilio de Tours, en el que oficialmente se prohibía la práctica quirúrgica a los clérigos. La Medicina monástica se extendió hasta el Concilio de Clermont en 1170, en que definitivamente se prohibió a los monjes ejercer la medicina, porque perturbaba la vida sacerdotal.

\section{Medicina escolástica}

La enseñanza de la medicina en las escuelas catedralicias estuvo a cargo del clero secular. Se trataba, en lo fundamental, de la doctrina hipocrática más elementos religiosos y especulaciones en torno a la orina y pulso del enfermo.

La mayor parte de la Edad Media transcurrió entre dos grandes epidemias: la de Justiniano en el siglo VI, que hasta el momento no se ha podido aclarar su causa y la Peste Negra bubónica que estalló en el siglo XIV. En este lapso se extendió la lepra por Europa y cuando ésta había declinado, apareció la sífilis.

\section{La Escuela de Salerno y las universidades}

En la ciudad de Salerno, a pocos kilómetros al sur de Nápoles, bajo la influencia árabe desde Sicilia y el sur de Italia, floreció allí en los siglos XI y XII, antes que las universidades, una escuela exclusivamente médica y por otro lado una "civitas hippocratica". El interés de esta escuela estaba centrado en el empirismo y la observación y no en el aspecto teórico-especulativo. El plan de estudios era tan bueno que lo adoptó después la Universidad de París.

Las primeras universidades se fundaron a comienzo del siglo XI: la de Bolonia en 1088, la de París en 1110 , a continuación la de Oxford en 1167 y la de Montpellier en 1181.

\section{La medicina árabe}

Fue una medicina hipocrática clásica. Los principales adelantos de la Medicina Árabe fueron: desarrollo de la cirugía, obstetricia y pediatría; observaciones clínicas en enfermedades infecciosas y oculares, construcción de hospitales, fomento de la salud pública; tratamiento de las heridas, luxaciones y esguinces; enseñanza de la urología y de las enfermedades del aparato digestivo.

\section{Médicos más famosos}

Rhazes y Avicena, ambos de origen persa. El primero, artista inclinado a la historia clínica. El segundo también muy observador, aristotélico interesado en lo general. Muy estimada es la monografía de Rhazes sobre la viruela y el sarampión, diferenciando por primera vez ambas enfermedades. Avicena alcanzó su mayor éxito con su Canon de Medicina, tratado de la teoría médica, estudiado durante seis siglos y traducido al latín en el siglo XII. Este siglo se ha considerado como el momento del renacimiento cultural de la Edad Media: a partir de dicha época, la medicina progresa febrilmente, las numerosas escuelas, el intercambio de ideas, de estudiantes y maestros entre ellas, la abundancia de textos nuevos y la relativa tranquilidad en que se desarrollaron los estudios permitieron obtener ideas originales. Nombres ilustres surgieron en todos los países y si su labor pudo quedar en parte anulada por la escolástica y la dialéctica, sirvió, sin embargo, para fijar las ideas sobre la cuales debería resurgir a su debido tiempo el verdadero renacimiento médico durante el siglo XVI ${ }^{4}$.

Tres figuras llenan el pensamiento médico de aquella época con ideas originales: Pedro de Abano, el profesor de Padua; aunque sus obras son disquisiciones filosóficas, se encuentran en ellas observaciones de tipo genial. Seguidor de los árabes, en ocasiones se enfrenta con la filosofía católica, por lo cual fue considerado herético teniendo dificultades con la Inquisición. La segunda figura fundamental, el franciscano Rogerio Bacon, fue un defensor de la experiencia en contra de la escolástica. Afirmaba la necesidad de experimentar, de reconocer la autoridad de las obras clásicas, pero sin seguirlas ciegamente. Comprendió el peligro que representaba la especulación escolástica para el desarrollo de las ciencias y luchó contra ella. El haber sido condenado a prisión y sus obras prohibidas, no influyó en la difusión de sus ideas que deben considerarse como las iniciadoras del método inductivo experimental. Debe citarse también al valenciano Arnaldo de Vilanova, que estudió en París, Montpellier, Salerno y Nápoles. En 
sus ideas se parece mucho a Bacon por su amor a la verdad y a la experiencia. Discute con autoridades como Galeno y Avicena a quienes niega en varias ocasiones. Defensor del hipocratismo, está a la vez impregnado de las ideas arábigas y de sus tendencias alquimistas. Vilanova fue profesor de medicina en Montpellier y desde la cátedra y con sus escritos, influyó poderosamente en la medicina de su época ${ }^{5}$.

Parecería importante señalar en la época mencionada al médico inglés Gilbertus Anglicus, que llegó a Canciller de la Universidad de Montpellier, en 1250. Fue autor del Compendium medicinae, impreso por primera vez en Lyon en 1510, que contiene un "Libro de Fiebres". Habría sido el primero en comprobar la contagiosidad de la viruela, describiendo muy bien la lepra y la rubéola.

\section{Petrus Hispanus}

Algunos médicos medievales se interesaron en sus escritos por los problemas terapéuticos, alcanzando popularidad durante varios siglos. Destaca entre ellos Pedro Juliao Rebello, mejor conocido como Petrus Hispanus, Maestro Julián y con otros nombres más, cuyos antecedentes históricos y biográficos, me impulsaron a escribir con algún detalle sobre su persona ${ }^{6}$.

Según el doctor José Montero T., miembro de la Academia de Historia de la Medicina de Bolivia, "en los Anales de la Historia de la Medicina se menciona a Petrus Hispanus, que fue el Papa Juan XXI'. De nombre Pedro Juliao Rebello (o Pedro Rebuli Gialini) nacido en Lisboa, Portugal, alrededor de 1215 ó 1210, según el profesor Francisco Guerra, hijo del médico Juliao Rebelo y de Teresa Gil ${ }^{6,7}$.

En la Edad Media la educación universitaria incluía con frecuencia una formación en medicina y teología. Por consiguiente no sorprende que años más tarde el médico lusitano antedicho, cristianizado como Petrus Julianus Lusitanus, continuara sus estudios médicos y eclesiásticos casi simultáneamente. Asistió a la escuela catedralicia en Lisboa y concurrió a la Universidad de París para estudios superiores. Ahí tomó un gran número de ramos, incluyendo medicina y teología. Como base estudió lógica, física aristotélica y metafísica. Fue un gran sofista, logista, discutidor y teólogo. Su talento médico debe haber sido considerable, porque en 1247 fue contratado por la Universidad de Siena para enseñar Medicina. En realidad, necesitaba el empleo debido a que alojaba en una parte de la ciudad muy pobre y tuvo que vender una vistosa copia de la Biblia que llevaba consigo. Pronto consiguió una vida respetable, siendo requerido como experto en casos médicos, participando en un juicio concerniente a una víctima de una enfermedad infecciosa. Petrus Hispanus estuvo muy interesado en la higiene de la ciudad y para él fue una buena elección testificar en dicho caso. Varios de sus folletos médicos estuvieron dedicados a las condiciones de vida, higiene y alimentación, como también relacionados con la evolución de las enfermedades. O sea, podría considerársele como higienista y salubrista.

Un libro de su autoría fue el Thesaurus Pauperum ("Tesoro de los Pobres"), de medicina general, con medicamentos simples y "efectivos", de preparación barata. En un pasaje típico recomienda "moscas tostadas para personas frenéticas con enfermedades nerviosas". Este libro aún era consultado en el siglo XV, siendo traducido al inglés. Consistía en un recetario sui generis (como todo en la medicina medieval) hecho para ser usado en la casa.

Otro texto suyo muy conocido, sobre filosofía aristotélica, fue el Sumulae Logicales. A Petrus Hispanus, además de las publicaciones mencionadas, se le ha reconocido un libro sobre enfermedades de los ojos (Liber de oculo). Alrededor de 26 copias de dicho libro se encontrarían en varios museos europeos, la mayoría en latín, el que fue rescatado entre los papeles o documentos de Miguel Ángel, aunque se piensa que sería un plagio de textos anteriores.

Uno de sus logros más notables habría sido descubrir que el glaucoma era una enfermedad con el "ojo duro".

Ptolomeo de Luca expresó su opinión contemporánea, al describir a Petrus Hispanus "en todos los casos, un escolar y en medicina, un especialista".

Robinson dice "que no debemos elogiarlo tan pronto; como el resto de sus contemporáneos creyó en brujos y demonios, aconsejó a los epilépticos llevar pergaminos con los nombres de los tres sabios del Este, Melchor, Gaspar y Baltazar. Aún en la época en que los remedios eran valorados de acuerdo con su repugnancia, Petrus logro distinguirse, como el campeón de los terapeutas del estiércol"'.

En todo caso, desde 1247 Petrus Hispanus fue profesor de Medicina y Oftalmología en la Universidad de Siena, ejerciendo más de 12 años, continuando con la escritura de varios tratados sobre Medicina y Lógica, cuya vigencia en las universidades duraron casi 300 años?

Las carreras paralelas de Petrus en Medicina y Teología fueron muy exitosas. En 1272 fue promovido a arzobispo de Braga; en 1273 se le adjudicó el capelo cardenalicio. Un año después fue médico de cabecera del Papa Gregorio $\mathrm{X}$ y asistió al segundo Concilio de Lyon.

Finalmente el año 1276 fue elegido Papa en la ciudad italiana de Viterbo, adoptando el nombre de Juan XXI. Duró en la sede pontificia únicamente ocho meses, encontrando fatalmente la muerte en la Catedral de Viterbo, en la que había mandado construir una especie de estudio personal o biblioteca. Durante la construcción, fue un día a revisar personalmente el estado de las obras, pero las vigas y piedras del edificio se le vinieron encima, falleciendo el 20 de mayo de $1277^{7,10}$. 
Para Pedro Lain Entralgo, "Petrus Hispanus fue uno de los grandes médicos y sabios del siglo XIII, que junto a sus esfuerzos cientificos consiguieron una influencia decisiva en la Iglesia y en la política"11.

\section{Resumen}

El Papa Juan XXI, de nombre Pedro Rebuli Giuliani, nacido en Lisboa, Portugal, alrededor de 1215, conocido como Petrus Hispanus, Maestro Julián, Pedro de España y otros nombres; junto con los estudios médicos, realizó los de teología, física aristotélica y metafísica en la Universidad de París. Nombrado Profesor de Medicina y Oftalmología en la Universidad de Siena en 1247. Además de diversos escritos sobre medicina, lógica y filosofía, fue autor del Tesaurus Pauperum ("El Tesoro de los Pobres"), recetario con medicamentos simples y baratos, de uso casero. Fue arzobispo de Braga y Cardenal en 1272 y 1273 , respectivamente. Elegido Papa en 1276, falleció trágicamente el 20 de mayo de 1277. Precede a este escrito un boceto sobre Medicina Medieval, con acento en los siglos XII y XIII.

\section{Referencias bibliográficas}

1.- Willius F A, Dry T J. A History of the heart and the circulation. Saunders, Filadelfia. USA. 1948.

2.- Marti-Ibáñez F. A prelude to Medical History. M.D. Publications. New York. USA. 1961.

3.- Ruiz Moreno A. La medicina en la legislación medieval española. Ed. El Ateneo. Buenos Aires. Rep. Argentina. 1946.

4.- Laval Manrique E. Apuntes sobre Historia de la Medicina: Edad Media y Renacimiento. (inéditos).

5.- Somolinos D'Ardois G. Historia de la Medicina: Edad Media. Ed. Pormaca. Méjico. 1964.

6.- Guerra F. Historia de la Medicina. $3^{\text {a }}$. Ed. Ediciones NormaCapitel. Madrid, España. 2007.

7.- Montero T J. Juan XXI, el Papa Médico. Arch Bol Hist Med 2005, 11: 112-5.

8.- Blanchard D. Papa Juan XXI, oftalmólogo. Doc Ophtal 1995, 89: 75-84.

9.- Robinson V. Historia de la Medicina. Tudor Publishing Co. New York. USA. 1936.

10.- Enciclopedia de la Religión Católica. Tomo V. p. 872. Ed. Rafael Salvi. Barcelona. España. 1953.

11.- Lain Entralgo Pedro. Historia Universal de la Medicina. Tomo III. Salvat Ed. Madrid. España. 1973. 